\title{
SYMPOSIUM ON SPORTS MEDICINE
}

Held at the Royal Society of Medicine, London, May 25th 1977

The General Practitioner and Sports Medicine

H. Evans Robson

39 Linkfield Road, Mountsorrel, Leicestershire

The general practitioner with an interest in sports medicine has several opportunities of practising this, both in his own premises, and outside. A knowledge of the basic principles can be applied to the rehabilitation of the sick and injured general patients, and motivate them to return to work, to their hobbies, or to the school physical education programme with the least delay. If one limb is injured, the other three should be exercised. Skilled guidance is needed to suggest suitable activities for the child with a soft-tissue injury, asthma, a congenital cardiac lesion or malnutrition. A patient's job may be sedentary, but enquiries about his hobbies often reveal causes of over-use injuries; the clerk with backache whose weight-training is random and unsupervised, the man with "rheumatism" in his shoulder who does not mention a deep dive a few days before with inadequate decompression, the horse woman with a stiff jaw who has not had her antitetanus vaccination, - all three examples from personal practice experience. A knowledge of the stresses of sport is an essential for proper examination of students entering physical education colleges, divers, racing drivers, athletes requesting pre-season examinations, or the middle-aged starting keep-fit classes. Too often, the temptation is to play safe, - "rest it!" "at your age, give it up!"

Opportunities for more specialised work may come through clinical assistantships in departments of rheumatology and rehabilitation, orthopaedic clinics, or accident and emergency services, but may be difficult to promote unless the consultant in charge is at least tolerant to have someone with an interest in sports medicine practice it in his department. Too many regard sports injuries as being voluntarily self-inflicted, and of less priority than others of similar aetiology caused by drunken driving, smoking or over-eating. Working in $\dot{a}$ department with a consultant who is a sports medicinew enthusiast, and knowledgeable in this field (not always the same thing) can be very rewarding, and a few arew lucky enough to obtain posts in one of the very fews specialised sports injuries or sports medicine clinics.

Local sports clubs, professional football clubs, and governing bodies of sport all need (but often fail to take steps to obtain) medical advisers, and welcome offers from doctors interested particularly in that specises sport. They often expect many medical services, at very. short notice, and without any reward. The satisfaction? of being with the club, participating in its sociak activities, perhaps playing, may be considered sufficient reward, but demands are often unreasonable, partiő cularly if only one doctor in an area is interested in sport, and is expected to attend, simultaneously, the local team's football match, the school sports, a gym-5 kana, and accompany the away team, in the unlikelys event that an injury requiring his attention will occur in any of these venues. His most useful place will be at his consulting room, where the injured can be brought ton him. The biggest service he could render the clubs in his town is to encourage some of the officials of each clubs to attend his classes and obtain an adequate knowledge of first-aid. Some sports, such as boxing, are compelled to have a doctor in attendance, and others such as show-jumping, certainly should, but there are not? enough doctors to go round to have one with every? sports venue. The doctor, physiotherapist and radiographer should be available at a central point where they can help any sportsman in the area, and not just one club. 